\title{
USO DE PLACEBOS EM PESQUISAS COM FINS COMERCIAIS: LIMITAÇÕES JURÍDICAS À LUZ DO ORDENAMENTO BRASILEIRO
}

Placebo use in research with commercial purposes: legal restrictions in the light of the Brazilian legal system

${ }^{1}$ Pontifícia Universidade Católica do Paraná. Curitiba/PR, Brasil. Correspondência: Fernanda Schaefer Rivabem. E-mail: ferschaefer@hotmail.com. 


\section{RESUMO}

Muito se discutem as pesquisas em seres humanos com uso de placebos sob o ponto de vista bioético, em especial à luz dos princípios bioéticos da autonomia, justiça e equidade. No entanto, não desconsiderando a importância dessas discussões, o assunto deve ser pensado também sob seu aspecto jurídico, particularmente no que se refere às pesquisas com fins comerciais. O presente artigo, a partir de pesquisa bibliográfica interdisciplinar, tem por objetivo discutir, à luz do ordenamento jurídico brasileiro, como devem ser tratadas as relações jurídicas decorrentes das pesquisas com uso de placebos financiadas por laboratórios e farmacêuticas e como devem ser aferidas as responsabilidades em caso de danos provocados ao pesquisado.

\section{Palavras-Chave}

Código de Defesa do Consumidor; Direito à Informação; Nocebo; Placebo; Responsabilidade.

\section{ABSTRACT}

There are many ethical discussions about the use of placebo in research with humans. These discussions often occur from a bioethical standpoint, particularly in the light of the bioethical principles of autonomy, justice and equity. However, and without disregarding the importance of these discussions, the legal aspect should also be considered, particularly concerning medical research with commercial purposes. This article, from a literature interdisciplinary review, aims to discuss, in the light of the Brazilian legal system, how research using placebo and financed by laboratories and pharmaceutical companies should be tackled and how to assess the liability arising from this research in case of damage caused to the participants.

\section{Keywords}

Brazilian Consumer's Code; Liability; Nocebo; Placebo; Right to Information. 


\section{Medicamentos e sociedade de consumo}

Medicamentos e tratamentos médicos, em suas mais variadas conformações, são utilizados pela humanidade há séculos ${ }^{1}$. No entanto, no século XXI, em pleno andamento da sociedade de consumo, procedimentos médicos e fármacos viraram objeto de consumo, o que vem levando não só a uma constante banalização do acesso e do uso de medicamentos - em especial, impulsionado pelas grandes campanhas de marketing -, como também à massificação das pesquisas - não só das que se destinam ao desenvolvimento de novos fármacos que atendam a esses "novos" desejos, mas também aquelas que fazem o acompanhamento de seu uso após o ingresso no mercado de consumo.

Se é verdade que a história da medicina demonstra que muitos progressos médicos só puderam ser obtidos a partir da pesquisa com seres humanos, verdade também é que na sociedade de consumo a saúde e o bem-estar se tornaram objetos de desejo e, nesse cenário, as pesquisas biomédicas vêm ganhando um espaço cada vez mais ampliado, agora impulsionadas pelo apelo publicitário, pelo constante acesso da população à informação e pelos espantosos avanços tecnológicos.

\section{Nesse contexto, afirma Baggio}

que, se por um lado o direito de acesso à medicação adequada para o tratamento de um problema de saúde é direito fundamental, complementar ao direito à saúde, não se pode ignorar o fato de que o usuário de medicamentos de modo geral é consumidor e precisa ter respeitados os seus direitos básicos, como informação, transparência, proteção à vida e segurança ${ }^{2}$.

E essas questões também se apresentam nas pesquisas com o uso de placebos, que envolvem não apenas interesses privados, mas também interesses sociais, e que contêm em si um grande paradoxo: o dever jurídico ${ }^{3}$ impõe que se informe ao pesquisado que ele receberá placebos e quais são os possíveis efeitos (princípio da

\footnotetext{
${ }^{1}$ Vide: SCLIAR, M. Cenas médicas: uma introdução à história da medicina. Porto Alegre: Artes e Ofícios, 2002. 2BAGGIO, A. C. Publicidade de medicamentos, automedicação e a (hiper)vulnerabilidade do consumidor idoso. Repensando os Direitos do Consumidor, v. 3, OAB/PR. No prelo.

${ }^{3} \mathrm{O}$ princípio da boa-fé, um dos pilares contemporâneos das relações jurídicas privadas, impõe consigo uma série de deveres, denominados deveres anexos (acessórios, instrumentais, funcionais, tutelares, laterais ou de conduta) como correção, cuidado, segurança, informação, cooperação, sigilo etc. São deveres que exigem uma constante "fiscalização" do comportamento dos sujeitos envolvidos na relação jurídica, uma vez que têm por objetivo o alcance da finalidade socioeconômica da relação obrigacional e dos respectivos interesses envolvidos. "Não estão estes deveres laterais orientados para o interesse no cumprimento do dever principal de prestação. Caracterizam-se por uma função auxiliar de realização positiva do fim contratual e de proteção à pessoa e aos bens da outra parte contra os riscos de danos concomitantes. Servem, ao menos as suas mais típicas funções, o interesse na conservação dos bens patrimoniais ou pessoais que podem ser afetados em conexão com o contrato, independente do interesse no cumprimento. Trata-se de deveres de adoção de determinados comportamentos, impostos pela boa-fé em vista do fim do contrato, dada a confiança que o contrato fundamenta, comportamentos variáveis com as circunstâncias concretas da situação". (PINTO, C.A.M. Cessão de contrato. São Paulo: Saraiva, 1985).
} 
informação e da transparência); no entanto, essa informação pode fazer a utilidade da pesquisa se perder por completo, uma vez que o efeito placebo não se apresentará de forma espontânea.

Os novos conhecimentos sobre o corpo humano e as potencialidades anunciadas pelas ciências biomédicas afetam diretamente bens considerados indisponíveis e juridicamente protegidos: vida e saúde. Por isso, o presente artigo tem por objetivo apresentar o significado da expressão "placebo", indicar os efeitos placebo e nocebo e, a partir deles, identificar os deveres jurídicos limitadores das pesquisas com placebos em seres humanos e as consequências jurídicas (à luz do ordenamento brasileiro) do financiamento (por laboratórios e farmacêuticas) de pesquisas com essas substâncias.

\section{Utilização de placebos em pesquisas com seres humanos}

A expressão "placebo" tem origem no latim: placeo, placere, que tinha o sentido genérico de agradar, dar prazer, satisfazer. Etimologicamente, portanto, o conceito se aproxima da ideia de que a medida médica está sendo adotada mais para agradar o paciente do que propriamente para tratá-lo.

No contexto médico, o termo foi pela primeira vez utilizado no século XVIII (1863), quando os médicos ingleses William Gull e Henry Sutton utilizaram água com menta para tratar pacientes com febre reumática a fim de avaliarem o desenvolvimento natural da doença e o papel dos remédios fornecidos na época ${ }^{4}$.

A partir de então, na literatura médica, placebo passou a ser definido "como substâncias que comprovadamente não possuem as propriedades físico-químicas de uma terapêutica efetiva, ainda que, em sua aparência, forma, cor ou qualquer outra

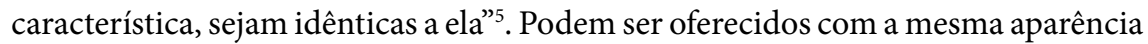
que teria um medicamento (pílula, líquido ou injetável), mas também podem ser oferecidos como um tratamento: cirurgias simuladas (sham procedures), aplicação local de pomadas e cremes ou até benzimentos e amuletos. Sobre as pesquisas realizadas com o uso de placebos, Rocha et al., citando Horvath, esclarecem que:

A conveniência de um delineamento placebo pode ser avaliada em termos de sua capacidade de isolar os componentes ativos das terapias efetivas. Nesse sentido, o pesquisador precisa distinguir os componentes considerados ativos do tratamento (fatores específicos ou inerentes) dos componentes não ativos (fatores não específicos ou comuns) ou mesmo dos elementos externos

\footnotetext{
${ }^{4}$ PARENTE, R.C.M.; OLIVEIRA, M.A.P.; CELESTE, R.K. Qual é o valor do placebo em pesquisas clínicas? Femina, v. 39, n. 4, p. 178-179, abr. 2011. Disponivel em: <http://files.bvs.br/upload/S/0100-7254/2011/v39n4/ a2476.pdf>.

${ }^{5}$ ROCHA, M.M.; DEL PRETTE, Z.A.P.; DEL PRETTE, A. Placebo na pesquisa psicológica: algumas questões conceituais, metodológicas e éticas. Revista Brasileira de Terapias Cognitivas, v. 4, n. 2, p. 39, 2008. Disponível em: <http://pepsic.bvsalud.org/pdf/rbtc/v4n2/v4n2a04.pdf>. doi: 10.5935/1808-5687.20080014.
} 
que podem produzir mudanças psicológicas. Para esta meta, um placebo efetivo ou qualquer tipo de grupo-controle deve satisfazer pelo menos dois critérios: (a) controlar ou reduzir ao máximo as variáveis não específicas, o que é mais provável quando o grupo placebo e o experimental têm o menor número de variáveis comuns possíveis; (b) emparelhar os grupos terapêuticos em todos os aspectos, com exceção do componente ativo que está sendo isolado e investigado na terapia ${ }^{6}$.

\section{Ainda segundo Rocha et al.,}

a pesquisa com placebos têm por objetivo investigar experimentalmente a eficácia de uma droga ${ }^{7}$ ou procedimentos, utilizando como controle um tratamento simulado como forma de isolar os possíveis efeitos físicos ou bioquímicos de eventuais melhoras ou curas decorrentes da expectativa de mudança, crença ou confiança do paciente. Traz implícita a ideia de que efeitos físicos e psicológicos podem ser separados ${ }^{8}$.

Por isso, a pesquisa ${ }^{9}$ com placebos pode ser realizada em três grandes dimensões: a pesquisa puramente acadêmica; a pesquisa financiada por laboratórios/farmacêuticas ou com fins comerciais; e a indicação feita pelo médico

\footnotetext{
${ }^{6}$ Apud ROCHA, M.M.; DEL PRETTE, Z.A.P.; DEL PRETTE, A. op. cit., p. 47.

${ }^{7}$ Vale aqui esclarecer em que sentido o termo "droga" está sendo usado. Segundo os conceitos técnicos adotados pela Agência Nacional de Vigilância Sanitária (Anvisa), droga é "substância ou matéria-prima que tenha finalidade medicamentosa ou sanitária". Medicamento "é o produto farmacêutico, tecnicamente obtido ou elaborado, com finalidade profilática, curativa, paliativa ou para fins de diagnóstico". Remédio "é qualquer substância ou recurso utilizado para obter cura ou alívio". Fármaco "designa qualquer composto químico que se utiliza com fim medicinal". Portanto, droga aqui é utilizada em sentido amplo como sinônimo de qualquer substância ou produto utilizado com intenção de modificar ou explorar sistemas fisiológicos ou estados patológicos (Organização Mundial da Saúde).

${ }^{8}$ ROCHA, M.M.; DEL PRETTE, Z.A.P.; DEL PRETTE, A. op. cit., p. 40.

'Segundo a Anvisa, estudo clínico é "qualquer investigação em seres humanos, objetivando descobrir ou verificar os efeitos farmacodinâmicos, farmacológicos, clínicos e/ou outros efeitos de produto(s) e/ou identificar reações adversas ao produto(s) em investigação, com o objetivo de averiguar sua segurança e/ou eficácia". Os estudos clínicos podem ser realizados nas seguintes fases: "fase pré-clínica: aplicação de nova molécula em animais, após identificada em experimentações in vitro como tendo potencial terapêutico; Fase I: avaliação inicial em humanos (20 a 100) e tolerância em voluntários saudáveis; é o primeiro estudo em seres humanos em pequenos grupos de pessoas voluntárias, em geral sadias, de um novo princípio ativo, ou nova formulação. Estas pesquisas se propõem a estabelecer uma evolução preliminar da segurança e do perfil farmacocinético e, quando possível, um perfil farmacodinâmico; Fase II (Estudo terapêutico piloto): primeiros estudos controlados em pacientes, para demonstrar efetividade potencial da medicação (100 a 200); visa demonstrar a atividade e estabelecer a segurança a curto prazo do princípio ativo, em pacientes afetados por uma determinada enfermidade ou condição patológica; Fase III: estudos internacionais, de larga escala, em múltiplos centros, com diferentes populações de pacientes para demonstrar eficácia e segurança (população mínima aprox. 800); visam determinar o resultado do risco/benefício a curto e longo prazo das formulações e do princípio ativo, bem como determinar o valor terapêutico; Fase IV: realizada após a aprovação para comercialização do produto para identificar efeitos adversos pouco frequentes ou não esperados; estudos de suporte de marketing; estudos adicionais comparativos e novas formulações". AGÊNCIA NACIONAL DE VIGILÂNCIA SANITÁRIA - ANVISA. Pesquisa clínica. Disponível em <http://www.anvisa.gov. $\mathrm{br} /$ medicamentos/pesquisa/def.htm>. Acesso em: 10 out. 2015. As pesquisas com uso de placebos, portanto, podem ser realizadas em estudos clínicos das fases I a IV, em qualquer das dimensões apontadas.
} 
diretamente ao próprio paciente ${ }^{10}$. Essas formas de pesquisa são comumente utilizadas (o que não significa que não sejam controversas) quando constatada a falta de um fármaco considerado padrão-ouro ${ }^{11}$ ou pela simples desconfiança do pesquisador na avaliação subjetiva do sujeito da pesquisa.

A discussão sobre o uso de placebos em pesquisas ou na prática clínica não é nova. A primeira reflexão foi proposta com o Código de Nuremberg ${ }^{12}$ (1947), que impôs como principais princípios das pesquisas com seres humanos: o consentimento do pesquisado; a ilegalidade da coerção; a beneficência e a não maleficência.

As questões levantadas pelo código também foram objeto de reflexão pela Declaração de Helsinque (atualizada em 2013), documento da Associação Médica Mundial que também direciona eticamente as pesquisas médicas com seres humanos e que aponta como princípios fundamentais a beneficência e a não maleficência e o respeito à autonomia do pesquisado.

Até 2013, a Associação Médica Mundial vedava a pesquisa com placebos nas situações em que houvesse tratamento eficaz disponível. A partir da revisão do texto e talvez cedendo às forças de $\operatorname{mercado}^{13}$, a Declaração de Helsinque passou a admitir pesquisas com placebos mesmo quando houver tratamento eficaz disponível:

33. Os benefícios, riscos e ônus e efetividade de uma nova intervenção devem ser testados contra aquele(s) da(s) melhor(es) intervenção(ões) comprovada(s), exceto nas seguintes circunstâncias:

Quando não existe intervenção comprovada, o uso de placebo, ou não intervenção, é aceitável; ou

Quando, por razões metodológicas convincentes e cientificamente sólidas, o uso de qualquer intervenção menos efetiva que a melhor comprovada, o uso do placebo, ou não intervenção para determinar a eficácia ou segurança de uma intervenção, é necessário para determinar a eficácia ou segurança de uma intervenção e os pacientes que recebem qualquer intervenção menos efetiva que a melhor comprovada, placebo, ou não intervenção, não

\footnotetext{
${ }^{10}$ No Brasil, as áreas que mais concentram pesquisas com placebos são: Neurologia e Psiquiatria (26,2\%), Imunologia (9,6\%), Odontologia (7,8\%) e Ginecologia (6\%) (JORDÃO, C.E.; MÊDOLA, P.R.; LOPES, L.C.; ROSALEN, P.L. Uso de placebo em experimentos clínicos envolvendo seres humanos no Brasil. Revista de Direito Sanitário, São Paulo, v. 9, n. 2, p. 31-46, jul./out. 2008. Disponível em: <http://www.revistas.usp. br/rdisan/article/view/13115/14918>. http://dx.doi.org/10.11606/issn.2316-9044.v9i2p31-46).

${ }^{11} \mathrm{O}$ método padrão-ouro para se determinar a eficácia de terapias é a detecção de uma diferença significativa entre os efeitos de um agente farmacologicamente ativou ou procedimento e de um placebo inerte, avaliados em um ensaio clínico randomizado (PARENTE, R.C.M.; OLIVEIRA, M.A.P.; CELESTE, R.K. op. cit., p. 177).

${ }^{12}$ CÓDIGO de Nuremberg. Tribunal Internacional de Nuremberg. Disponível em: <http://www.gtp.org.br/new/ documentos/nuremberg.pdf>. Acesso em 10 out. 2015.

${ }^{13} \mathrm{~A}$ justificativa apresentada afirmou que a liberação se fazia necessária em virtude de muitos países associados à Associação Médica Mundial permitirem a realização de ensaios clínicos com utilização de placebo, mesmo havendo tratamento eficaz. Ora, a Declaração deve ser fruto da discussão ética entre os associados, e não do que cada um dos associados impõe como sua necessidade ética.
} 
estarão sujeitos a riscos adicionais de danos graves ou irreversíveis como resultado de não receber a melhor intervenção comprovada. Extremo cuidado deve ser tomado para evitar abuso desta opção ${ }^{14}$.

Não satisfeitos com os novos rumos da Declaração de Helsinque, os médicos integrantes da Confederação Médica Latino-Americana e do Caribe (Confemel), também no ano de 2013, assinaram a Declaração de Pachuca (México), que veda a utilização de placebos quando há tratamento médico eficaz disponível - resgatando, portanto, a determinação anterior de Helsinque. Esse mesmo posicionamento foi tomado pelo Conselho Federal de Medicina do Brasil na Resolução n. 1885/2008 ${ }^{15}$ e no Código de Ética Médica (Resolução n. 1931/2009) ${ }^{16}$, que proíbem a participação de médicos em ensaios clínicos quando houver tratamento efetivo já comprovado. A falta de acordo entre os médicos e as associações representativas é, portanto, evidente. Fato é que pesquisas com seres humanos não se subordinam apenas a declarações éticas, mas também se subordinam a normas jurídicas.

No Brasil, atualmente, as pesquisas que envolvam seres humanos subordinam-se à regulamentação exarada pelo Ministério da Saúde (MS), por meio do Conselho Nacional de Saúde (CNS) e da Comissão Nacional de Ética em Pesquisa (Conep) ${ }^{17}$. O CNS

há quase duas décadas assumiu a responsabilidade de debater os aspectos éticos relacionados com as pesquisas que envolvem seres humanos. [...] o CNS tem por objetivo, além de evitar abusos e proteger os sujeitos das pesquisas, contribuir para o desenvolvimento seguro de investigações que possam realmente beneficiar a sociedade brasileira ${ }^{18}$.

Para isso, conta com o auxílio de uma complexa estrutura, composta pelo sistema formado pelo Conep e pelos Comitês de Ética em Pesquisa (CEPs).

A principal função do Conep é analisar os aspectos éticos das pesquisas em áreas temáticas especiais como genética; reprodução humana; pesquisas em populações indígenas; pesquisas que envolvam biossegurança e desenvolvimento de novas tecnologias para a saúde. Trata-se de instância colegiada e multidisciplinar de natureza consultiva, educativa e institucional cuja principal atribuição é coordenar todos os CEPs - que, devidamente credenciados, devem avaliar, autorizar e acompanhar todas as propostas de pesquisa que envolvem seres humanos no Brasil, salvaguardando os direitos e a dignidade dos sujeitos e assegurando a qualidade das pesquisas.

\footnotetext{
${ }^{14}$ DECLARAÇÃO de Helsinque da Associação Médica Mundial (WMA). Disponível em: <http://www.amb.org.br/ arquivos/_downloads/491535001395167888_DoHBrazilianPortugueseVersionRev.pdf>. Acesso em 10 out. 2015.

${ }^{15}$ CONSELHO FEDERAL DE MEDICINA. Resolução $n$. 1885, de 22 de outubro de 2008. Disponível em: < http://www.portalmedico.org.br/resolucoes/cfm/2008/1885_2008.htm>. Acesso em: 08 set. 2016.

${ }^{16}$ CONSELHO FEDERAL DE MEDICINA. Código de Ética Médica. Disponível em: <http://portal.cfm.org.br/ index.php?option=com_content\&view=category\&id=9\&ltemid=122>. Acesso em: 08 set. 2016.

${ }^{17}$ Comissão do CNS.

${ }^{18}$ MINISTÉRIO DA SAÚDE. Conselho Nacional de Saúde. Manual operacional para comitês de ética em pesquisa. 4. ed. Disponível em: <http://conselho.saude.gov.br/web_comissoes/conep/aquivos/ materialeducativo/Manual_ceps_v2.pdf>. Acesso em 10 abr. 2015.
} 
Atualmente a pesquisa com seres humanos está eticamente regulamentada no Brasil pela Resolução n. 466/2012, do CNS. Em seu item III.3.b, a Resolução, além de exigir prévia fundamentação da necessidade da pesquisa em seres humanos (independente de ter ela finalidade comercial ou acadêmica), exige que os pesquisadores justifiquem a

utilização de placebo em termos de não maleficência e de necessidade metodológica, sendo que os benefícios, riscos, dificuldades e efetividade de um novo método terapêutico devem ser testados, comparando-o com os melhores métodos profiláticos, diagnósticos e terapêuticos atuais. Isso não exclui o uso de placebo ou nenhum tratamento em estudos nos quais não existam métodos provados de profilaxia, diagnóstico ou tratamento ${ }^{19}$.

Também a Resolução n. 466/2012 do CNS exige que, no termo de consentimento esclarecido, seja explicado ao declarante, quando pertinente, "sobre a possibilidade de inclusão do participante em grupo de controle ou placebo, explicitando, claramente, o significado dessa possibilidade" (item I.V4.b). De fato, ao disciplinar o uso de placebo em pesquisas com seres humanos, o Conselho Nacional de Saúde deixou a critério do pesquisador ("quando pertinente") informar sobre a inclusão do paciente em um grupo que utilizará placebo - o que é, sem dúvida, paradoxal.

O posicionamento do CNS faz sentido se analisado exclusivamente à luz do que se pretende clinicamente ao se realizar uma pesquisa com placebos. Porém, juridicamente é um posicionamento que não se sustenta por: ferir a dignidade da pessoa humana; retirar a autonomia do paciente (direito de personalidade); fragilizar o dever jurídico de informação ao autorizar o julgamento subjetivo do pesquisador - assim, colocando em xeque o próprio direito do paciente de não querer se submeter à pesquisa e resgatando o já superado e decrepito paternalismo médico.

Eticamente, portanto, o primeiro problema na pesquisa com placebos é a evidente violação da autonomia do pesquisado ou do paciente. Em termos bioéticos, a autonomia pressupõe competência e livre arbítrio do indivíduo, pressupostos que dificilmente se encontram nessas pesquisas não só porque os termos de consentimento não usam linguagem adequada, mas porque, pelo próprio objetivo da pesquisa com placebos, muitas informações acabam sendo omitidas do paciente propositadamente a fim de garantir a espontaneidade do efeito. Ora, se informações importantes são omitidas, como afirmar a autonomia do paciente? Como o paciente/pesquisado

\footnotetext{
${ }^{19}$ Item III.3.b. Para fins de responsabilização a Resolução n. 466/2012, deverá ser interpretada à luz do sistema jurídico, em especial: Constituição Federal, Código Civil e Código de Defesa do Consumidor, conforme se estudará adiante. CONSELHO NACIONAL DE SAÚDE. Resolução n. 466, de 12 de dezembro de 2012. Disponível em: <http://conselho.saude.gov.br/resolucoes/2012/Reso466.pdf>. Acesso em: 08 set. 2016.
} 
poderia agir com liberdade, buscando o que for melhor para seu bem-estar, se não está recebendo todas as informações necessárias ao exercício de sua autodeterminação ${ }^{20}$ ?

Além da violação do princípio da autonomia, parece também evidente a violação dos princípios bioéticos da equidade e da justiça. A equidade não se confunde com a igualdade, ou seja, esta é consequência desejada por aquela. É por meio da equidade que se alcança a igualdade - a primeira é um dos caminhos práticos éticos para a realização dos direitos humanos. É princípio que não se traduz em tratar todos de maneira igual, pois são diferentes as situações biomédicas, e sim em guardar proporcionalidade nas ações e intervenções. Como essa proporcionalidade pode ser respeitada quando se submete um grupo a pesquisa com placebos, sabendo haver outro tratamento eficaz disponível? Como garantir justiça quando um grupo está recebendo tratamento eficaz e o outro está recebendo placebo?

Além do problema principiológico, outra contradição aparece dentro da própria Declaração de Helsinque, item 6, que define que

o principal objetivo de pesquisa médica envolvendo seres humanos é compreender as causas, a evolução e os efeitos das doenças e melhorar as intervenções preventivas, diagnósticas e terapêuticas (métodos, procedimentos e tratamentos). Mesmo a melhor intervenção comprovada deve ser continuamente avaliada através de pesquisa no que diz respeito a sua segurança, efetividade, eficiência, acessibilidade e qualidade ${ }^{21}$.

Dessa forma, é preciso questionar: qual a real necessidade de pesquisa com placebos quando a segurança, a efetividade e a eficiência do medicamento já estão mais do que comprovadas e documentadas? Por isso é importante se estudarem os limites jurídicos para além dos limites meramente éticos.

\section{Efeito placebo e efeito nocebo}

A expressão "efeito placebo" relaciona-se às reações positivas psicofisiológi$\operatorname{cas}^{22}$ decorrentes da administração de um placebo semelhante a um medicamento (oral ou injetável); ou da realização de cirurgias simuladas; ou da utilização de um

\footnotetext{
${ }^{20}$ Afirma Lorenzetti "que o exercício da liberdade deriva em uma regra de autonomia que importa a impossibilidade de decidir sem condicionamentos externos. Não se trata de decidir sem limites, já que estes existem [...]. Trata-se que dentro do espaço de autonomia concedido pelo ordenamento jurídico o sujeito possa decidir por si mesmo". E é exatamente disso que se trata a autonomia: de autodeterminação em uma perspectiva solidarística, o que Ihe confere contornos mais amplos. LORENZETTI, R.L. Fundamentos do direito privado. São Paulo: Ed. Revista dos Tribunais, 1998. p. 502.

${ }^{21}$ DECLARAÇÃO de Helsinque da Associação Médica Mundial (WMA), cit.

${ }^{22}$ Vários mecanismos psicológicos contribuem para o efeito placebo: expectativa (espera de efeitos positivos) e condicionamento (associação repetida entre um estímulo neutro e uma droga ativa - estímulo não condicionado) podem resultar na habilidade de estímulo neutro, por ele mesmo dar uma resposta semelhante a do não condicionado; memória; motivação; aprendizado; redução da ansiedade; sistema compensatório (PARENTE, R.C.M.; OLIVEIRA, M.A.P.; CELESTE, R.K. op. cit., p. 177 e ss.).
} 
equipamento ineficaz; ou até de uma experiência ou um símbolo terapêutico. Dentre os efeitos reconhecidos, os que mais ganham atenção dos cientistas são os efeitos psicológicos que, por óbvio, não curam nem promovem a remissão da doença, mas de alguma forma provocam alívio dos sintomas. Nesse sentido, afirma Rocha et al.:

Verifica-se, atualmente, um crescente reconhecimento das interações entre mecanismos psicológicos ou psicossociais, de um lado, e os bioquímicos ou biológicos de outro. As intervenções biológicas ocorrem em um organismo que é também psicológico e social e, portanto, produzem reações psicológicas; por outro lado, as intervenções psicológicas ocorrem em um organismo que é biológico e são mediadas por processos também bioquímicos, grande parte deles ainda não totalmente explicados ${ }^{23}$.

O efeito placebo depende da natureza da doença, da influência do meio em que o doente está inserido e da compreensão do doente sobre o tratamento que lhe é oferecido e, por isso, doenças cujos sintomas são mais subjetivos e influenciados por desordens emocionais respondem melhor às terapias com placebos.

No entanto, nem sempre os efeitos produzidos são benéficos ou positivos. Para designar esses efeitos negativos, utiliza-se a expressão efeito "nocebo" - do latim nocere (infligir dano) -, que se relaciona às reações psicofisiológicas desfavoráveis decorrentes da utilização de um placebo. Constitui-se da expectativa negativa do paciente em relação à pesquisa, efeito que muitas vezes é determinado pela própria imposição do dever de informação.

O efeito nocebo pode estar associado: às informações sobre as reações adversas que podem ser causadas pelo medicamento (vômitos, diarreia, dor de cabeça, cansaço, urticária); ao preço da consulta ${ }^{24}$ ou do medicamento; à forma como os profissionais (médicos, enfermeiros, auxiliares) se relacionam com o pesquisado; à forma como o medicamento ou tratamento é apresentado e suas características físicas ${ }^{25}$.

Tanto o efeito placebo como o nocebo não são vinculados à farmacologia dos medicamentos ou à eficácia dos tratamentos, uma vez que não têm ação eficaz sobre a doença ou sobre seus sintomas. São efeitos que têm origem em percepções psicofisiológicas do paciente e que geram, por diversos mecanismos, resultados diretos sobre a saúde ou sobre o bem-estar do enfermo.

\footnotetext{
${ }^{23}$ ROCHA, M.M.; DEL PRETTE, Z.A.P.; DEL PRETTE, A. op. cit., p. 41.

${ }^{24} \mathrm{Algumas}$ pesquisas demonstraram que, quanto maior o preço da consulta, maior é a expectativa positiva do paciente com relação ao diagnóstico e ao tratamento e vice-versa (BALLONE, G.J; MOURA, E.C. O placebo e a arte de curar. Disponível em: <http://www.psiqweb.med.br>. Acesso em 10 abr. 2015).

${ }^{25}$ Algumas pesquisas demonstraram que há preferência para a eficácia dos placebos de uso tópico em comparação aos de uso oral (Id. Ibid., [s.p.]).
} 


\section{Uso de placebos em pesquisas financiadas por laboratórios ou farmacêuticas}

\section{Aplicabilidade do Código de Defesa do Consumidor}

O Código de Defesa do Consumidor $(\mathrm{CDC})^{26}$ aplica-se a todas as espécies de relações de consumo ${ }^{27}$ quando presentes, concomitantemente, os seguintes elementos: consumidor, fornecedor, produto ou serviço e vulnerabilidade. Entretanto, antes de afirmar a aplicabilidade do CDC às pesquisas com placebos e fins comerciais, é preciso passar por dois raciocínios:

(a) A relação entre pesquisador e pesquisado seria uma relação contratual atípica subordinada às leis civis, uma vez que quem está efetivamente prestando um serviço (e não o faz com habitualidade) é o pesquisado (paciente), que se oferece voluntária e gratuitamente para participar da pesquisa, comportando-se como "cobaia”. Portanto, a responsabilidade decorrente dessa relação seria contratual (artigo 389 e seguintes do Código Civil $-\mathrm{CC}^{28}$ ) e objetiva (artigo 927, parágrafo único, $\mathrm{CC}$ - atividade de risco ${ }^{29}$ ).

${ }^{26}$ BRASIL. Lei n. 8.078, de 11 de setembro de 1990. Dispõe sobre a proteção do consumidor e dá outras providências. Disponível em: <http://www.planalto.gov.br/ccivil_03/leis/L8078.htm>. Acesso em: 08 set. 2016.

${ }^{27}$ Relação de consumo é uma relação jurídica formada entre fornecedor e consumidor (polos de interesse) tendo como objeto de interesse produto ou serviço, segundo os critérios expressamente definidos pela legislação de defesa do consumidor. Afirma Miragem que "é preciso referir que, de acordo com a técnica legislativa adotada no direito brasileiro, não existe no CDC uma definição específica sobre o que seja relação de consumo. Optou o legislador nacional por conceituar os sujeitos da relação, consumidor e fornecedor, assim como seu objeto, produto ou serviço. No caso, são considerados conceitos relacionais e dependentes" (Grifos no original). (MIRAGEM, B. Direito do consumidor. São Paulo: Ed. Revista dos Tribunais, 2008. p. 80).

${ }^{28}$ BRASIL. Lei n. 10.406, de 10 de janeiro de 2002. Institui o Código Civil. Disponível em: <http://www. planalto.gov.br/ccivil_03/leis/2002/L10406compilada.htm>. Acesso em: 08 set. 2015.

${ }^{29}$ Vale aqui destacar o sentido e alcance do artigo 927, parágrafo único, CC. Este dispositivo estabelece a responsabilidade objetiva para quem realiza atividade que, por sua natureza, implique risco para outrem. A expressão "atividade" aqui deve ser entendida como serviço, trabalho, ocupação, atuação reiterada, habitual, organizada profissional ou empresarialmente para realizar fins econômicos. Quanto à expressão "natureza" da norma, deve ser compreendida como atividade que envolve risco inerente, risco intrínseco à atividade, risco que não pode ser evitado (ainda que observada toda a diligência possível) e que deve ser suportado. A expressão "risco" deve ser compreendida como situação de incerteza, e não como algo eventual, como infortúnio ou insegurança, ou seja, refere-se àquilo que razoavelmente se espera da atividade porque intimamente ligado à sua natureza. Nesse sentido, afirma Barboza que "os riscos gerados por atividades e que se busca exatamente descobrir ou dimensionar o seu grau de nocividades, como a pesquisa e experimentação em humanos, à evidência desconhecidos e imprevisíveis, embora inerentes à atividade, não podem ser tolerados, havendo responsabilidade por eventuais danos, com fundamento no princípio da solidariedade e como imperativo da tutela da pessoa humana". (BARBOZA, H.H. Responsabilidade civil em face das pesquisas em seres humanos: efeitos do consentimento livre e esclarecido. In: MARTINS-COSTA, J.; MÖLLER, L.L. (Orgs.). Bioética e responsabilidade. Rio de Janeiro: Forense, 2009. p. 214). Portanto, as pesquisas com seres humanos enquadram-se na ideia da atividade de risco (risco integral) justamente porque o risco aqui é inerente, pois “quem se dispõe a exercer alguma atividade perigosa terá que fazê-lo com segurança, de modo a não causar dano a outrem, sob pena de ter que por ele responder independentemente de culpa" (CAVALIERI FILHO, S. Programa de responsabilidade civil. São Paulo: Atlas, 2006p. 186). 
(b) No entanto, quando se trata de utilização de placebos em ensaios clínicos com fins comerciais, o pesquisado deverá ser equiparado a um consumidor (artigo 29, CDC). O CDC estabeleceu três espécies de consumidor equiparado, previstas nos artigos $2^{\circ}$, parágrafo único, 17 e 29 (normas de extensão do campo de incidência do CDC). Em todos esses dispositivos, "o que se percebe é a desnecessidade da existência de um ato de consumo (aquisição ou utilização direta), bastando para a incidência da norma que [o consumidor] esteja exposto às situações previstas no Código" ${ }^{30}$ - como no caso do sujeito de pesquisa que é destinatário de práticas comerciais e da formação e execução de contratos de pesquisas com fins comerciais. Afirma Marins que:

Considerando o ditame do art. 29 à luz da interpretação lógica e gramatical, é forçoso reconhecer-se que a extensão pretendida, ao equiparar a consumidores todas as pessoas, determináveis ou não, está disciplinando relações jurídicas de toda ordem, mesmo que não sejam relações de consumo, e consumidor não se trate. Se a legislação não estabelece limitações ou discrimens à equiparação, não cabe a intérprete fazê-lo, especialmente se não existe qualquer antinomia normativa a ser expurgada, não existindo também qualquer conflito com o sistema seja considerando o microssistema das relações de consumo, ou nosso sistema jurídico como um todo ${ }^{31}$.

Portanto, diz-se equiparado porque, embora haja em aparência uma relação contratual civil ${ }^{32}$ entre pesquisado e pesquisador, o pesquisado que receber o placebo em pesquisas com fins comerciais estará exposto aos efeitos de todas as atividades do pesquisador no mercado, podendo ser, inclusive, por elas prejudicado. Além disso, o pesquisado está sujeito a diversas práticas abusivas relacionadas nos artigos de 30 a 41 e de 46 a 54, CDC. Sob esse ponto de vista, pode-se afirmar que a relação entre pesquisador e pesquisado não é uma relação de consumo standard, mas a ela se equipara quando ocorre um fato danoso resultante da utilização do placebo em pesquisas com fins comerciais (artigos 14, 17 e 20, CDC) ou quando constadas práticas abusivas em qualquer dos momentos da contratação (artigo 29, CDC). Prescinde-se, portanto, da efetiva participação da pessoa na relação de consumo, bastando que ela esteja exposta às práticas comerciais. Nesse sentido, destaca Miragem ${ }^{33}$ que:

Trata-se de definição de consumidor equiparado que maiores possibilidades oferece para aplicação das normas de proteção do

\footnotetext{
${ }^{30}$ MIRAGEM, B. op. cit., p. 83.

${ }^{31}$ MARINS, J. Proteção contratual do CDC a contratos interempresariais, inclusive bancários. Revista do Direito do Consumidor, São Paulo, v. 18, p. 99, 1996.

${ }^{32} \mathrm{~A}$ premissa aqui adotada é de que toda relação de consumo é uma relação civil, embora a recíproca, por óbvio, não seja verdadeira.

${ }^{33}$ MIRAGEM, B. op. cit., p. 85.
} 
CDC a quem não seja qualificado como consumidor em sentido estrito, destinatário final do produto ou serviço. [...]. Atualmente, a aplicação do conceito do artigo 29 permite converter o CDC em paradigma de controle de todos os contratos de direito privado brasileiro. [...] resulta apenas equiparar a consumidor, e portanto, aplicar as regras sobre contratos e práticas comerciais do $\mathrm{CDC}$, quando estiver presente a vulnerabilidade do contratante, de modo que se justifique a equiparação em vista da finalidade de assegurar o equilíbrio entre desiguais.

Outra não é a situação do sujeito de pesquisa submetido a estudos com placebos para fins comerciais. Trata-se, sem dúvida, de contratante vulnerável fática, jurídica e economicamente e que não pode ficar à mercê, tão somente, de regulamentos éticos e administrativos emitidos por órgãos vinculados ao Ministério da Saúde. Diante de sua reconhecida vulnerabilidade, é necessária sua equiparação como consumidor a fim de lhe ampliar a tutela e evitar práticas abusivas que coloquem em risco sua saúde e segurança.

Sabe-se que a indústria farmacêutica ocupa grande espaço na economia global, representando atividade dinâmica e de alta lucratividade. Seja produzindo medicamentos e produtos médicos, seja realizando pesquisas, seja patrocinando pesquisas com medicamentos, não há dúvida de que assume papel de fornecedora, detendo não só o poder econômico sobre essas atividades, como também muitas vezes detendo o conhecimento técnico a respeito do medicamento ou do placebo que está pesquisando.

Quanto ao pesquisado, equiparando-o ao consumidor vítima do evento (artigo 17, CDC) ou sujeito a práticas abusivas (artigo 29, CDC), é importante também destacar sua condição de vulnerabilidade ${ }^{34}$ (artigo $4^{\circ}$, inciso I, CDC) - ou melhor, hipervulnerabilidade (ou vulnerabilidade potencializada) -, não só pelas condições impostas por sua própria doença, mas também pelas condições impostas pela pesquisa e pela ausência ou pouca informação a ela relacionada e pelas pressões decorrentes do marketing e dos discursos de biopoder (a saúde é "dever de cada um e o objetivo de todos"). O pesquisado, ao consentir em participar da pesquisa, não está apenas a ela aderindo, mas concedendo permissão ao pesquisador para realizar ensaios sobre seu corpo ou sua mente. Por isso, Meirelles afirma que:

\footnotetext{
${ }^{34}$ Para Moraes, o reconhecimento da vulnerabilidade decorre do princípio da igualdade, sendo que vulnerabilidade, sob o enfoque jurídico, é, então, o princípio pelo qual o sistema jurídico positivado brasileiro reconhece a qualidade ou condição daquele(s) sujeito(s) mais fraco(s) na relação de consumo, tendo em vista a possibilidade de que venha(m) a ser ofendido(s) ou ferido(s), na sua incolumidade física ou psíquica, bem como no âmbito econômico, por parte do(s) sujeito(s) mais potente(s) da mesma relação. (MORAES, P.V.P. Código de Defesa do Consumidor: o princípio da vulnerabilidade no contrato, na publicidade, nas demais práticas comerciais: interpretação sistemática do Direito. 3. ed. atual. e ampl., de acordo com o Código Civil de 2002. Porto Alegre: Livr. do Advogado, 2009. p. 125).
} 
É vulnerável não só aquele que sofre, que padece de alguma enfermidade e que, por isso, está à mercê dos tratamentos, das pesquisas e experiências científicas que lhe mostrem algum caminho na busca da cura ou da diminuição do seu sofrer, mas também aquele que, ainda que não se encontre em grave estado de debilidade física, não tem condições de compreender tudo o que lhe é informado, dado o seu grau de instrução.[...].

Não é possível esquecer que ele [paciente] é um ser humano e, como tal, carrega consigo um conjunto único, individual e simultâneo de experiências do passado, realidades do presente e expectativas do futuro. Ee esse conjunto que lhe faz ser mais do que mero paciente [sujeito da pesquisa], um indivíduo. Embora a doença seja a mesma de tantos outros, os sintomas sejam de há muito conhecidos pela Medicina, em suma, embora o presente seja aparentemente igual para todos os pacientes que padecem do mesmo mal, as experiências do passado e as expectativas futuras fazem com que a situação presente seja vista de modo diferente de um indivíduo para outro ${ }^{35}$.

O CDC reconhece a vulnerabilidade do consumidor como fruto da desigualdade (fática, técnica e econômica) existente entre este e o fornecedor e, por isso, a ele dedica especial proteção, qualquer que seja a natureza da relação de consumo em que esteja inserido. Essa fragilidade do consumidor (mesmo do equiparado) manifesta-se de forma ainda mais acentuada em pesquisas com fins comerciais que envolvam placebos, uma vez que partes da informação indispensável ao exercício da autonomia do pesquisado serão necessariamente omitidas para preservar os fins da pesquisa.

Desta forma, pode-se afirmar que a relação pesquisador-pesquisado em pesquisas com fins comerciais não é apenas um mero fato social, mas uma relação jurídica (contratual) que se caracteriza por possuir sujeitos de direitos e obrigações (pesquisador e pesquisado); um objeto jurídico (saúde); um fato jurídico relevante (pesquisa com produtos de saúde); e garantias legais (em especial, proteção constitucional à dignidade, à saúde, à vida e à integridade física e psíquica).

Presentes todos os pressupostos, não restam dúvidas quanto à aplicabilidade do Código de Defesa do Consumidor às pesquisas com placebos financiadas por laboratórios ou congêneres, cujos contratos subordinam-se indistintamente a todas as suas normas, vez que seus dispositivos são de natureza cogente, impositivos e irrenunciáveis pela vontade de qualquer das partes.

\section{Dever de informação e transparência}

\footnotetext{
${ }^{35}$ MEIRELLES, J.M.L. Consentimento livre, dignidade e saúde pública: o paciente hipossuficiente. In: RAMOS, C.L.S.; TEPEDINO, G.; BARBOZA, H.H.; GEDIEL, J.A.P; FACHIN, L.E.; MORAES, M.C.B. (Orgs.). Diálogos sobre direito civil: construindo uma racionalidade contemporânea. Rio de Janeiro: Renovar, 2002. p. 353-354.
} 
A democratização da medicina impôs o reconhecimento da autonomia do paciente e, com isso, determinou que toda relação médico-paciente e pesquisador-pesquisado seja informada por diversos princípios, dentre os quais podem-se destacar: privacidade e confidencialidade, boa-fé objetiva, veracidade, informação, transparência e confiança. São todos princípios que possuem conteúdo ético e que se destacam também por sua imposição jurídica.

Interessa ao presente artigo os deveres de informação e transparência (ambos decorrentes da boa-fé objetiva ${ }^{36}$ ), pois são princípios cuja aplicação pode se tornar difícil em pesquisas com placebos e fins comerciais em virtude dos objetivos atribuídos a elas.

Já se afirmou anteriormente: a pesquisa com placebos é paradoxal, pois, ao mesmo tempo em que se impõe o dever de informar, essa mesma informação pode tornar inútil a pesquisa ou seus resultados. Nesse sentido, Rocha et al. explica que:

Mesmo na ausência de fatores comprovadamente terapêuticos, a estruturação de um grupo placebo precisa garantir que este gere, no paciente, a mesma credibilidade e o mesmo nível de expectativa de melhora que o grupo experimental (Rains \& Penzien, 2005), o que implica oferecer uma racional, adequada e convincente explicação sobre o atendimento a ser desenvolvido. No âmbito da Medicina, a utilização de delineamentos com grupos placebo vem geralmente associada a um procedimento de pesquisa denominado de "ensaio clínico duplo-cego randomizado", como forma de controlar fatores psicológicos incidentais aos ingredientes ativos pesquisados (Baskin et al., 2003). Nesse delineamento, os envolvidos não têm conhecimento das condições de tratamento a que estão submetidos (no caso dos pacientes), que estão conduzindo (no caso dos terapeutas) ou que estão avaliando (no caso dos avaliadores) $)^{37}$.

\footnotetext{
${ }^{36}$ Boa-fé objetiva (princípio da eticidade). Cláusula geral que encontra fundamento no princípio constitucional da solidariedade (artigo $3^{\circ}$, inciso III, da Constituição Federal de 1988) e que possui três grandes funções: integrativa/interpretativa, fonte de deveres e de controle ao exercício das liberdades contratuais. Sendo cláusula geral, é preciso assentar seus fundamentos na tutela da pessoa humana sob pena de se esvaziar completamente seu conteúdo. Portanto, analisada como norma de conduta, impõe às partes contratantes deveres de conduta leal e transparente. E complementa Negreiros: “a inserção da formulação do princípio da boa-fé neste contexto de transformações do direito dos contratos é indispensável na medida em que a sua aplicação importa, para usar a linguagem corrente - adiante questionada - numa 'limitação' à autonomia privada, seja no âmbito das restrições legislativas elaboradas com fundamento no princípio, seja, sobretudo e de forma imediata, através da atuação judicial, que, com base na boa-fé objetiva, impõe deveres às partes contratantes em franca desconsideração pela vontade manifestada por uma ou, até mesmo, por ambas as partes" (NEGREIROS, T. Fundamentos para uma interpretação constitucional do princípio da boa-fé. Rio de Janeiro: Renovar, 1998, p. 187). BRASIL. Constituição da república Federativa do Brasil de 1988. Disponível em: <http://www.planalto.gov.br/ccivil_03/constituicao/constituicaocompilado. htm>. Acesso em: 08 set. 2016.

${ }^{37}$ ROCHA, M.M.; DEL PRETTE, Z.A.P.; DEL PRETTE, A. op. cit., p. 45.
} 
Assim, por exemplo, o problema de pesquisas que utilizam o duplo-cego randomizado está justamente na ausência de transparência e de informação ao pesquisado, que não sabe previamente se está no grupo placebo ou no grupo com tratamento eficaz e muitas vezes sequer é comunicado da existência desses dois grupos.

O dever de transparência ( $\operatorname{artigo} 4^{\circ}$, caput, CDC) nas relações negociais tem por principal objetivo harmonizar os interesses das partes negociantes, fomentando uma aproximação negocial honesta, digna, leal e sincera, favorecendo a cooperação mútua e o comportamento correto. Transparência traz consigo a ideia de informação clara, objetiva e precisa sobre o serviço ou produto que está sendo oferecido.

Já o dever de informação (artigo $6^{\circ}$, inciso III, CDC), intimamente ligado ao dever de transparência, não abrange apenas as características principais da pesquisa a ser realizada, mas afeta todo o conteúdo do contrato e do termo de consentimento firmado entre pesquisador e pesquisado. Nas palavras de Lorenzetti:

O dever de informar alude a uma conduta imposta a alguém, a fim de que esclareça a outra pessoa relacionada, ou que pode se relacionar com ele, aspectos que conhece e que diminuem, ou podem diminuir, a capacidade de discernimento, ou de previsão, do outro, se tais dados não se subministram.

Poderíamos dizer que se trata do dever jurídico obrigacional, de causa diversa, que corresponde ao possuidor de informação vinculada com uma relação jurídica, ou com a coisa envolvida na prestação, ou atinente a atividades suscetíveis de causar danos a terceiros, ou a um dos contratantes, derivados de tais danos, e cujo conteúdo é o de pôr em conhecimento da outra parte, uma quantidade de elementos suficientes para evitar os danos ou a inferioridade contratual que se possa gerar na outra parte, caso tal informação seja fornecida ${ }^{38}$.

O pesquisado, portanto, é detentor de um direito subjetivo de informação que resguarda sua autodeterminação (liberdade de escolha racional, consciente e refletida - direito fundamental). Assim, uma informação clara quer dizer comunicação minuciosa, meticulosa, precisa qualitativa e quantitativamente, que não deixa qualquer dúvida a respeito do que está sendo pesquisado. É a maneira inequívoca de se transmitir uma informação sobre a investigação, não deixando qualquer imprecisão ou dúvida a respeito das intenções do pesquisador. A clareza da informação certamente garante sua transparência, o que, como já se afirmou anteriormente, parece de certa forma inconciliável com os objetivos das pesquisas com placebos.

Uma informação objetiva é aquela que corresponde à realidade da pesquisa, indicando o que se almeja, o que se pretende, os fins claros e as obrigações

${ }^{38}$ LORENZETTI, R.L. op. cit., p. 514-515. 
a serem assumidas, sem hesitação ou malícia. Busca uma linguagem acessível ao paciente individualizado, que deverá ser capaz de reter a informação, sopesar o que lhe foi dito e decidir racional e conscientemente de acordo com suas legítimas expectativas. E aqui outro problema se apresenta: as expectativas criadas no pesquisado podem ter sido diretamente influenciadas pela mídia ou pela forma como o pesquisador apresentou o ensaio, o que sem dúvida acabará viciando o consentimento para dela participar.

Portanto, o dever de informação obriga o pesquisador e o patrocinador da pesquisa ao cumprimento da obrigação (ônus) de informar com clareza, objetividade e adequação o seu pesquisado (consumidor equiparado), sob pena de tornar o contrato e o termo de consentimento nulos de pleno direito quando não observado corretamente esse mandamento.

Compreendidas como princípios e deveres jurídicos, informação e transparência não devem ser pensadas como simples elementos éticos-formais necessários à validade dos termos de consentimento esclarecido: são, sim, parte da essência do contrato realizado entre pesquisador e pesquisado e, por isso, devem proporcionar o amplo e prévio conhecimento de todas as condições da pesquisa, dos direitos do pesquisado e das responsabilidades dos patrocinadores e pesquisadores.

\section{Responsabilidade do pesquisador e da entidade patrocinadora da pesquisa com fins comerciais}

A Lei n. 8.078/1990 - que institui o CDC - introduziu uma concepção social de contrato na qual se valoriza não só o momento da manifestação da vontade, como também os efeitos daquele contrato na sociedade. A lei passa a ser limitadora dos contratos e legitimadora da autonomia privada, visando a proteger a ordem econômica e social. Deixa, portanto, de ser norma supletiva e interpretativa para tornar-se cogente.

O CDC, no Título I, Capítulo IV, trata da qualidade de produtos e serviços, da prevenção e da reparação dos danos, indicando dispositivos que possibilitam, inclusive, a responsabilização solidária dos fornecedores. A primeira Seção desse capítulo, sob o título "Da Proteção à Saúde e Segurança", estabelece critérios de nocividade ou periculosidade dos produtos ou serviços e enuncia deveres de informação impostos aos fornecedores, instaurando um verdadeiro sistema de garantia à qualidade e adequação de produtos e serviços.

Considerando esses dispositivos, todos com fundamento na dignidade da pessoa humana (artigo $1^{\circ}$, inciso III, da CF/88), na solidariedade (artigo $3^{\circ}$, inciso I, da $\mathrm{CF} / 88$ ) e no direito constitucional à saúde (artigos $6^{\circ} \mathrm{e} 196$, da CF/88), de antemão

\footnotetext{
${ }^{39}$ BRASIL. Lei n. 8.078, de 11 de setembro de 1990, cit.
} 
já é possível afirmar que qualquer pesquisa que seja nociva ou perigosa ao pesquisado é vedada expressamente.

Poder-se-ia argumentar que, de alguma forma, toda a pesquisa traz risco $^{40}$ ao pesquisado, e isso é uma verdade. No entanto, o que o CDC veda é que o pesquisador realize pesquisas que acarretem riscos desproporcionais ${ }^{41}$ à saúde e à segurança dos pesquisados. Observados esses dispositivos, portanto, impõem-se aos pesquisadores e financiadores um dever de diligência e de informação sobre a pesquisa que pretendem efetivar e a segurança que dela se pode esperar, pois, havendo a mínima dúvida sobre o potencial ofensivo da pesquisa, não deve ser ela realizada.

Assim, com relação às pesquisas com placebos com fins comerciais é aplicável (por equiparação) o disposto nas Seções II a V do Capítulo II do CDC - capítulo que tutela a prevenção e reparação de danos decorrentes de relações de consumo, baseado em um sistema de responsabilidade legal. O legislador preocupou-se em estabelecer noções e critérios para comercialização de produtos e serviços, criando duas grandes órbitas de proteção (que não são excludentes entre si): a primeira, que tutela a incolumidade física e psíquica do consumidor, definindo a responsabilidade decorrente de danos oriundos de fato do produto ou do serviço (acidente de consumo - artigos 12 a 17, CDC); e a segunda, que visa à tutela da incolumidade econômica do consumidor, estipulando a responsabilização por vícios do produto ou do serviço (incidentes de consumo - artigos 18 a 25, CDC).

Qualquer falha em pesquisa com placebos que coloque em risco a saúde e a segurança do pesquisado será enquadrada como um acidente de consumo (fato do serviço, vício de segurança - artigo 14, CDC), considerando-se como serviço defeituoso a pesquisa que não fornece a segurança que o pesquisado dela poderia

\footnotetext{
${ }^{40}$ Destaca Barboza que "considera-se que toda pesquisa envolvendo seres humanos envolve risco e é admitida quando: a) oferece elevada possibilidade de gerar conhecimento para entender, prevenir ou avaliar um problema que afete o bem-estar dos sujeitos da pesquisa e de outros indivíduos; b) o risco se justifique pela importância do benefício esperado; e c) o benefício seja maior, ou no mínimo igual, ao das outras alternativas já estabelecidas para a prevenção, o diagnóstico e o tratamento. 0 dano eventual poderá ser imediato ou tardio, comprometendo o indivíduo ou a coletividade [...]. O risco da pesquisa compreende qualquer possibilidade de dano à dimensão física, psíquica, moral, intelectual, social, cultural ou espiritual do ser humano, em qualquer fase de uma pesquisa ou dela decorrente" (BARBOZA, H.H. op. cit., p. 218-219).

${ }^{41}$ Para minimizar os riscos a pacientes submetidos a controle placebo, Baldwin et al. (2003) indica os seguintes cuidados no delineamento da pesquisa: (a) estabelecimento de um termo detalhado de consentimento informado sobre o tratamento; (b) seleção cuidadosa dos participantes; (c) monitoramento constante do estado dos participantes; (d) pronta disponibilidade do pesquisador em atender o cliente entre os encontros; (e) informe periódico ao paciente de que ele pode abandonar o estudo a qualquer momento que desejar; (f) redução da duração do tratamento placebo aos limites mínimos do teste de validade científica; (g) estabelecimento de critérios claros para exclusão do cliente no decorrer do atendimento, por exemplo, quando não está respondendo adequadamente ao tratamento; e (h) inclusão, no protocolo de atendimento, de providências com clientes excluídos do atendimento ou que ainda apresentam as queixas ao final deste (ROCHA, M.M.; DEL PRETTE, Z.A.P.; DEL PRETTE, A. op. cit., p. 48-49).
} 
esperar levando em conta as explicações que lhe foram fornecidas no momento da contratação (violação da legítima expectativa).

Nesses casos, o pesquisador, a instituição onde se realizam as pesquisas e o patrocinador da pesquisa responderão solidariamente (artigo $7^{\circ}$, parágrafo único, CDC) pela reparação dos danos causados (v.g. danos morais, materiais, perda de uma chance, desvio produtivo, entre outros) - sendo que o pesquisador responderá subjetivamente (mediante a aferição de culpa), enquanto a instituição e o patrocinador responderão objetivamente (independentemente de culpa) pelos danos causados. Além da reparação, o pesquisador, a instituição e o patrocinador assumem responsabilidade pela integral assistência aos sujeitos pesquisados, independentemente do dano ter sido previsto ou não no termo de consentimento. Tratando-se de fato do serviço, a vítima terá prazo de cinco anos para a propositura da ação indenizatória, contados do conhecimento do dano ou da verificação de sua autoria (artigo 27, CDC).

No entanto, se a falha não afetou diretamente a saúde e a segurança do pesquisado, causando danos de menor potencial ofensivo, estar-se-á diante do que se denomina de vício do serviço (vício de adequação), cuja forma de reparação está prevista no artigo 20, CDC. O vício de qualidade por inadequação é um defeito que não atinge o objeto específico da obrigação (prestação), mas compreende o próprio serviço. Na definição de $L o ̂ b o^{42}$ "vício, pois, é todo aquele que impede ou reduz a realização da função ou do fim a que se destinam o produto ou serviço, afetando a utilidade que o consumidor dele espera”.

No caso de vício da pesquisa com placebos com fins comerciais, o pesquisador, a instituição e o patrocinador responderão solidariamente (artigo $7^{\circ}$, parágrafo único, CDC) pela reparação dos danos causados, sendo a responsabilidade de todos considerada objetiva e o prazo da propositura da ação, de três anos contados do conhecimento do dano ou da verificação de sua autoria (artigo 206, parágrafo $3^{\circ}$, inciso $\mathrm{V}, \mathrm{CC})$.

Já quanto à violação dos deveres de informação e transparência e à quebra da legítima expectativa por práticas contratuais abusivas, deve-se lembrar de que a simples violação de princípios contratuais é suficiente para caracterizar a violação positiva do contrato ${ }^{43}$, instrumento utilizado para garantir a eficácia da boa-fé objetiva e os deveres dela decorrentes. Trata-se de uma forma de inadimplemento cujos efeitos variam caso a caso, podendo inclusive gerar indenização por perdas e danos. Reforça-se, dessa forma, os deveres de cooperação mútua, de lealdade e de transparência, impondo cuidado recíproco entre as partes negociantes. Tratando-se

\footnotetext{
${ }^{42}$ NETTO LÔBO, P.L. Responsabilidade por vício do produto ou do serviço. Brasília: Brasília Jurídica, 1996. p. 52.

${ }^{43}$ Constitui forma de inadimplemento contratual que independe da análise de culpa do contratante inadimplente, pois decorre da quebra de deveres anexos decorrentes da boa-fé objetiva.
} 
a relação entre pesquisado e pesquisador como relação negocial, informação e transparência estão reforçadas como deveres jurídicos impostos a ambas as partes.

As garantias constantes no $\mathrm{CDC}$ abrangem os riscos contra a vida e a saúde, protegem bens irrenunciáveis e compreendem os riscos contra o próprio patrimônio (material e imaterial) do consumidor. Trata-se de sistema que visa a realizar as legítimas expectativas dos pesquisados, tantas vezes criadas maliciosamente pelos próprios pesquisadores ou patrocinadores.

O sistema de garantias, aliado aos deveres de informação e transparência, pretende assegurar a seriedade nas relações negociais em todos os seus momentos e, no caso das pesquisas com placebos com fins comerciais envolvendo seres humanos: desde o momento em que o pesquisador se aproxima do pesquisado para convidá-lo a participar da pesquisa (pré-negocial); no momento em que o pesquisado aceita os termos da pesquisa e passa a ela se sujeitar (negocial); até o momento em que a pesquisa é encerrada (pós-negocial). Esses princípios permitem, portanto, a extensão da responsabilidade do pesquisador, da instituição e da empresa financiadora a todas as três fases dessa relação negocial.

O progresso biocientífico deve ser sempre utilizado em favor do paciente, pautado por princípios éticos e jurídicos mínimos que orientem o agir humano de acordo com as regras morais da sociedade. Assim, no Estado brasileiro, toda e qualquer intervenção sobre o corpo do paciente só será lícita se observados os princípios da autodeterminação da pessoa, da dignidade humana e da salvaguarda da vida, saúde, integridade física e psíquica, impondo-se, dessa forma, limites jurídicos a todo e qualquer tipo de pesquisa que tenha seres humanos como sujeitos.

\section{Considerações finais}

A preocupação com as pesquisas com seres humanos não é uma novidade deste início do século XXI. A novidade é o contexto em que estão inseridas: uma sociedade em que saúde e bem-estar passaram a ser objetos de desejo e de consumo; uma sociedade em que há constante acesso à informação (o que não significa ser uma informação de qualidade); uma sociedade em que discursos de biopoder se multiplicam velozmente.

É justamente nesse contexto de trocas rápidas, de informações efêmeras e de massificação das pesquisas biomédicas que se deve compreender o direito à saúde como um direito fundamental intimamente atrelado à dignidade da pessoa humana. É nesse contexto que o princípio da informação e o dever de transparência devem ser reconhecidos não apenas como deveres éticos impostos ao pesquisador, mas, antes disso, como deveres jurídicos (e assim devem ser compreendidos).

Por isso, quando se analisam pesquisas com placebos financiadas por laboratórios ou farmacêuticas, deve-se ter em conta um pressuposto essencial: o placebo não é uma substância inerte atuando sozinha; sua utilização deve ser vista dentro de 
um conjunto de sentidos e estímulos biopsicossociais que avisam ao paciente que um tratamento benéfico ou maléfico está sendo administrado.

Portanto, como qualquer outra pesquisa em seres humanos, as investigações que utilizam placebos podem apresentar benefícios, mas também trazer riscos à recuperação ou manutenção da saúde do sujeito pesquisado. Dessa forma, a relação entre pesquisador e pesquisado em pesquisas com placebos financiadas por laboratórios (e congêneres) deve ser compreendida como uma relação jurídica que se subordina especialmente aos princípios e valores da Constituição Federal. Pensar de outra forma autorizaria a fragmentação e instrumentalização da saúde em favor de necessidades muitas vezes criadas pelo próprio mercado de consumo e pela mídia.

\section{Referências}

AGÊNCIA NACIONAL DE VIGILÂNCIA SANITÁRIA - ANVISA. Conceitos técnicos. Disponível em: <http://www.anvisa.gov.br/medicamentos/conceito.htm>. Acesso em: 10 out. 2015.

Pesquisa clínica. Disponível em <http://www.anvisa.gov.br/medicamentos/pesquisa/ def.htm>. Acesso em: 10 out. 2015.

BAGGIO, A. C. Publicidade de medicamentos, automedicação e a (hiper)vulnerabilidade do consumidor idoso. Repensando os Direitos do- Consumidor, v. 3, OAB/PR. No prelo.

BALLONE, G.J; MOURA, E.C. O placebo e a arte de curar. Disponível em: <http://www. psiqweb.med.br>. Acesso em 10 abr. 2015.

BARBOZA, H.H. Responsabilidade civil em face das pesquisas em seres humanos: efeitos do consentimento livre e esclarecido. In: MARTINS-COSTA, J.; MÖLLER, L.L. (Orgs.). Bioética e responsabilidade. Rio de Janeiro: Forense, 2009.

CAVALIERI FILHO, S. Programa de responsabilidade civil. São Paulo: Atlas, 2006.

CÓDIGO de Nuremberg. Tribunal Internacional de Nuremberg. Disponível em: < http://www. gtp.org.br/new/documentos/nuremberg.pdf>. Acesso em 10 out. 2015.

JORDÃO, C.E.; MÊDOLA, P.R.; LOPES, L.C.; ROSALEN, P.L. Uso de placebo em experimentos clínicos envolvendo seres humanos no Brasil. Revista de Direito Sanitário, São Paulo, v. 9, n. 2, p. 31-46, jul./out. 2008. Disponível em: <http://www.revistas.usp.br/ rdisan/article/view/13115/14918>. http://dx.doi.org/10.11606/issn.2316-9044.v9i2p31-46.

LORENZETTI, R.L. Fundamentos do direito privado. São Paulo: Ed. Revista dos Tribunais, 1998.

MARINS, J. Proteção contratual do CDC a contratos interempresariais, inclusive bancários. Revista do Direito do Consumidor, São Paulo, v. 18, p. 94-103, 1996. 
MEIRELLES, J.M.L. Consentimento livre, dignidade e saúde pública: o paciente hipossuficiente. In: RAMOS, C.L.S.; TEPEDINO, G.; BARBOZA, H.H.; GEDIEL, J.A.P; FACHIN, L.E.; MORAES, M.C.B. (Orgs.). Diálogos sobre direito civil: construindo uma racionalidade contemporânea. Rio de Janeiro: Renovar, 2002. p. 347-377.

MINISTÉRIO DA SAÚDE. Conselho Nacional de Saúde. Manual operacional para comitês de ética em pesquisa. 4. ed. Brasília: Ed. Do Mi9nistério da Saúde, 2008. Disponível em: <http:// conselho.saude.gov.br/web_comissoes/conep/aquivos/materialeducativo/Manual_ceps_ v2.pdf>. Acesso em 10 abr. 2015.

MIRAGEM, B. Direito do consumidor. São Paulo: Ed. Revista dos Tribunais, 2008.

MORAES, P.V.P. Código de Defesa do Consumidor: o princípio da vulnerabilidade no contrato, na publicidade, nas demais práticas comerciais: interpretação sistemática do Direito. 3. ed. atual. e ampl., de acordo com o Código Civil de 2002. Porto Alegre: Livr. do Advogado, 2009.

NEGREIROS, T. Fundamentos para uma interpretação constitucional do princípio da boa-fé. Rio de Janeiro: Renovar, 1998.

NETTO LÔBO, P.L. Responsabilidade por vício do produto ou do serviço. Brasília: Brasília Jurídica, 1996.

PARENTE, R.C.M.; OLIVEIRA, M.A.P.; CELESTE, R.K. Qual é o valor do placebo em pesquisas clínicas? Femina, v. 39, n. 4, p. 177-182, abr. 2011. Disponível em: <http://files.bvs. br/upload/S/0100-7254/2011/v39n4/a2476.pdf>.

PINTO, C.A.M. Cessão de contrato. São Paulo: Saraiva, 1985.

ROCHA, M.M.; DEL PRETTE, Z.A.P.; DEL PRETTE, A. Placebo na pesquisa psicológica: algumas questões conceituais, metodológicas e éticas. Revista Brasileira de Terapias Cognitivas, v. 4, n. 2, p. 39-54, 2008. Disponível em:<http://pepsic.bvsalud.org/pdf/rbtc/v4n2/v4n2a04.pdf>. $10.5935 / 1808-5687.20080014$.

SCLIAR, M. Cenas médicas: uma introdução à história da medicina. Porto Alegre: Artes e Ofícios, 2002.

Fernanda Schaefer Rivabem - Pós-Doutora no Programa de Pós-Graduação Stricto Sensu em Bioética pela Pontifícia Universidade Católica do Paraná; doutora em Direito das Relações Sociais pela Universidade Federal do Paraná e Universidade do País Basco e Universidade de Deusto (Espanha); mestre em Direito Econômico e Social pela Pontifícia Universidade Católica do Paraná; graduada em Direito pela Pontifícia Universidade Católica do Paraná. Bolsista Capes. Professora e Coordenadora da Pós-Graduação Lato Sensu em Direito Médico e professora de Direito Civil e Biodireito do Curso de Direito do UniCuritiba. Advogada; membro da Comissão de Educação Jurídica e da Comissão de Estágio e Exame da Ordem dos Advogados - Seção Paraná. Curitiba/PR, Brasil. E-mail: ferschaefer@hotmail.com. 